\title{
Single Core Osmotic Pump (SCOP): Development of Single Layer Osmotic controlled release tablet for poorly soluble drug
}

\author{
Geeta M. Patel ${ }^{1 *}$ and Jayendra D. Patel ${ }^{1}$
}

\begin{abstract}
A new Single Core Osmotic Pump (SCOP) tablet which osmotically delivers high doses of low solubility drugSertraline Hydrochloride (SET) has been developed. The formulations were compared based on six comparative parameters namely, Q24(total release after 24hr), Q12(total release after 12hr),TL (lag time), RSQzero12 (R square of zero order equation for drug release in 12hr), RR12 (in vitro release rate for $12 \mathrm{hr}$ ) and T80\%(time require to deliver $80 \%$ of drug). The drug release profile from osmotic devices showed that the type of polymer and concentration in the core formulation can markedly affect the drug release. Increasing the amount of osmogent to an optimum level significantly increased Q12 and improved zero order release pattern of SET. Bioavailability enhancing additive, citric acid was added in core formulation, which has multifunction property like enhancedSET solubility, create osmotic pressure difference, act as flux regulating agent and make SET containing composition more hydrophilic. As a result, TL and T80\% were decreased and Q12 and RR12 were increased. Increasing concentration of PEG 4000 in the semipermeable membrane of the SCOP markedly decreased TL, T80\%and increased Q12, Q24 and RR12. Optimum aperture diameter for the formulations was determined to be $850 \mu \mathrm{m}$ for zero order release pattern. This study also revealed thatoptimization of SPM thickness is very important for approaching zero order kinetics.The developed SCOP system could be effective to formulate a single layer osmotic controlled release tablet of water insoluble drug with large dose.
\end{abstract}

\section{Introduction}

Over the past 50 years, with the recognition of the therapeutic advantages of controlled drug delivery systems, greater attention has been dedicated to development of controlled-release delivery systems. Among various technologies that have been used in the development of controlled drug delivery systems, osmotic pumps hold an important position [1-7]. These are devices that use osmotic pressure as an energy source to deliver drug at predetermined zero-order rates for extended period of time. Though different types of oral osmotic systems have been reported in the literature [8], the single most important osmotic delivery system is Theeuwes elementary osmotic pump [9]. In this system, the osmotic core is surrounded by a semi permeable membrane drilled with a drug delivery orifice. Once this system comes in contact with the gastrointestinal fluids, the osmotically driven water enters the system through the semi permeable membrane, dissolves the soluble agents and exits through the delivery orifice. Because these systems use osmotic pressure for the controlled delivery of the active compound(s), delivery rates are expected to be independent of gastrointestinal conditions [9].

The rate of drug release from osmotic pumps is dependent on total solubility and osmotic pressure of the core. Therefore, poorly water-soluble drugs do not create sufficient osmotic pressure

*correspondence: geekhappy2002@yahoo.co.in

'S K Patel Collge of Pharmaceutical education and Research, Gujarat, India. and are delivered at low rates. To over-come this problem, other types of osmotic pumps for poorly water-soluble drug have been designed $[10,11]$ In some cases, this problem may be solved by addition of a solubility-modulating agent to the core [12-14]. However, this approach is not satisfactory for cases where a large amount of the modulator is necessary. In addition, rapid depletion of the modulator from the system will cause the device to release the drug at nonuniform rates.

Literature review suggested that single-layer osmotic drug delivery of low solubility drug is possible [15-20], but do not define the limitations or optimal formulation factors for such systems. In the current investigation, factors that influence the successful delivery of low solubility API's from a single-layer osmotic system are investigated.

For the development of single core osmotic pump (SCOP), Sertraline Hydrochloride (SET) was selected as model drug. SET is most commonly prescribed for therapy of depressive illness, in the general dose range 50-200 mg day. SET also has poor aqueous solubility, particularly at $\mathrm{pH}$ values above 6 to 7 . This can result in low bioavailability. Patients are generally initiated on SETat a dose of $50 \mathrm{mg} /$ day or less. Patients who do not respond at the $50 \mathrm{mg}$ dose are given higher doses. If necessary to achieve efficacy, higher doses may be reached by gradual increases in dosage. Improved SET dosage forms which exhibit a lower incidence and/or severity of side effects would be advantageous because patient comfort and thus, compliance, would be improved and dosing could be initiated at doses higher than $50 \mathrm{mg}$ without the need for gradual increases. Initiation at higher starting doses would, in turn, be useful by potentially affecting a shorter onset of antidepressive action.

(C) 2012 Patel et al; licensee Herbert Publications Ltd. This is an open access article distributed under the terms of Creative Commons Attribution License (http://creativecommons.org/licensesby/2.0), This permits unrestricted use, distribution, and reproduction in any medium, provided the original work is properly cited 
Thus, such an improved SET dosage form which permits oral dosing of high doses of SET (e.g., $60 \mathrm{mg}$ and higher) with relatively reduced side effects would permit wider therapeutic application of SET therapy, and would accordingly provide a significant improvement in dosing compliance and convenience [21-22].

\section{Materials}

Sertraline Hydrochloride (SET) was a generous gift from Hetero Drugs Limited (Hyderabad,India). Natrosol (250 H, 250 L), Klucel (EXF, HF) were generous gifts from DKSH India Pvt Ltd. (Mumbai, India). PolyoxWSR Coagulant and Methocel were received as a gift samples from Colorcon Asia Pvt Ltd. (Goa, India). Xanthan Gum was received as a gift sample from Ottochemi (Mumbai, India). Cellulose acetate was received as a gift sample from Eastman Chemical Co. (USA). Neosorb P 30/60 was received as a gift sample from Roquette Asia Pvt. Ltd, Mumbai. Xylitol was received as a gift sample from Daniscolngradient, USA. Citric acid, Polyethylene glycol 4000 and Sodium lauryl sulphate were purchased from S. D. Fine Chemicals (Mumbai,India).The other chemicals used were of analytical grade.

\section{Experimental}

\section{Drug-excipients compatibility study}

Assessment of possible incompatibilities between an active drug substance and different excipients forms an important part of the preformulation stage during the development of dosage form. Differential Scanning Calorimeter (DSC TA-60WS) allows the fast evaluation of possible incompatibilities, because it shows changes in the appearance, shift of melting endotherms and exotherms, and/or variations in the corresponding enthalpies of reaction. The DSC thermograms of pure drug SET, polymer Natrosol 250HX, an osmotic agent Neosorb P 30/50 DC and a mixture of drug with polymer Natrosol 250HX, an osmotic agent Neosorb P 30/50 DC and mixture of drug with all excipients in ratio drug: excipients (1:1) used in formulation were recorded. The thermal analysis was performed in a nitrogen atmosphere at a constant heating rate of $10^{\circ} \mathrm{C} / \mathrm{min}$ over a temperature range of $40^{\circ} \mathrm{C}$ to $300^{\circ} \mathrm{C}$.

\section{Drug estimation}

UV determination was carried out for drug content uniformity and measure quantity of SET during dissolution test. The response of the sample solution was measured at $274 \mathrm{~nm}$. The amounts of SET present in the sample solution were determined by fitting the responses into the regression equation for SET. A calibration curve was plotted over a concentration range of $100-200 \mu \mathrm{g} / \mathrm{ml}$.

\section{Formulation development and optimization of core Tablet}

Core tablets were prepared by direct compression. In order to select water swellable polymer, formulation were prepared using $10 \% \mathrm{w} / \mathrm{w}$ core weight of Polyox Coagulant, Methocel K4M, Natrosol 250HX, Xanthan Gum and Klucel HF and their effects on release profiles were determined. The core compositions are summarized in (Table-1). SET was mixed with water swellable polymer for $10 \mathrm{~min}$. After passing this mixture through 40 mesh sieve, Neosorb P30/60 DC (osmotic agent) and Klucel EXF (binder) were added in geometric dilution and mixing continued for additional $10 \mathrm{~min}$. To this mixture, Sodium lauryl sulphate (wetting agent) and Acryflow-L (lubricant) were added and mixed for additional $5 \mathrm{~min}$. The blend was then compressed to tablet with an average weight of $695 \pm 10 \mathrm{mg}$ using rotary tablet machine (Rimek Mini Press-II) equipped with a $13 \mathrm{~mm}$ diameter round, plain and standard concave tooling. The average hardness of compressed tablets was $6.5 \pm 1.5 \mathrm{~kg} / \mathrm{cm}^{2}$.

Various formulation and dissolution parameters were analyzed to optimize SCOP. Various parameters, mainly, $\mathrm{Q}_{24}$ (quantity of the drug released within $24 \mathrm{~h}$ ), Q12 (quantity of the drug released within $12 \mathrm{~h}$ ), $\mathrm{TL}$ (lag time of the drug release from device), $\mathrm{RSQ}_{\text {ZERO } 12}$ (R square of release data of $12 \mathrm{~h}$ fitted to zero order equation), $\mathrm{RR}_{12}$ (in vitro release rate for $12 \mathrm{~h}$ ) and $\mathrm{T}_{80 \%}$ (time require to deliver $80 \%$ of drug), were used to compare different formulations. Formulations with acceptable $\mathrm{Q}_{24}$ (i.e., $\mathrm{Q}>70 \%$ ) and $\mathrm{Q}_{12}$ (i.e., $\mathrm{Q}>50 \%$ ) were adopted for further evaluations. Among selected formulations, those with $\mathrm{T}_{\mathrm{L}}>$ $2 \mathrm{~h}$ were rejected and other formulations were compared in terms of the RSQzero, $\mathrm{RR}_{12}$ and $\mathrm{T}_{80 \%}$.

\section{Coating and drilling}

Core tablets were coated in a conventional laboratory coating pan. Coating solution was prepared by dissolving 16 grams of cellulose acetate CA 398-10 and 8 grams of polyethylene glycol 4000 in a binary solvent mixture of acetone ( 356 grams) and water (20 grams). Various components of coating solution were added to solvent mixture in sequential manner. The component added first was allowed to dissolve before next component was added. Before starting coating, tablets were warmed at $40 \pm 5^{\circ} \mathrm{C}$ for 10 minutes and then coating solution was applied at a constant spray rate of 4-5 $\mathrm{ml} / \mathrm{min}$. Coating process was done on a batch of 100 tablets. Pan speed was maintained at $20 \mathrm{rpm}$ and hot air inlet temperature

\begin{tabular}{|c|c|c|c|c|c|c|}
\hline Ingredients & B1 & B2 & B3 & B4 & B5 & B6 \\
\hline $\begin{array}{l}\text { Sertraline } \mathrm{HCl}(\cong 200 \\
\mathrm{mg} \text { of } \mathrm{SET})\end{array}$ & 224 & 224 & 224 & 224 & 224 & 224 \\
\hline Polyox Coagulant & - & 60 & - & - & - & - \\
\hline HPMC K4M & - & - & 60 & - & - & - \\
\hline Natrosol $250 \mathrm{HX}$ & - & - & - & 60 & - & - \\
\hline Xanthan Gum & - & - & - & - & 60 & - \\
\hline Klucel HF & - & - & - & - & - & 60 \\
\hline Neosorb P30/60 DC & 322 & 262 & 262 & 262 & 262 & 262 \\
\hline Klucel EXF & 30 & 30 & 30 & 30 & 30 & 30 \\
\hline Citric acid & 105 & 105 & 105 & 105 & 105 & 105 \\
\hline SLS & 18 & 18 & 18 & 18 & 18 & 18 \\
\hline Acryflow - L & 6 & 6 & 6 & 6 & 6 & 6 \\
\hline
\end{tabular}

Table -1: Formulae of SCOP TABLET (mg tablet) 
was kept at $40 \pm 5{ }^{\circ} \mathrm{C}$. Coating was continued until desired $\%$ coat weight $(10 \%)$ was obtained on the core tablets. In order to investigate the effect of coating membrane including amount of plasticizer as well as thickness on drug release, osmotic tablets were coated with different concentration of plasticizer with different membrane thickness shown in Table 2.

Coated tablets were drilled through the one side of each coated tablet by standard mechanical micro drills. To minimize the effect of orifice size on the release of the active, orifice of $850 \mu$ mdiameter was drilled on the tablets.

\section{In vitro release studies}

In vitro release studies of different formulations were performed according to USP apparatus II, paddle method (Dissolution test apparatus-TDT-06T, Electrolab, India). Paddle speed was maintained at $50 \mathrm{rpm}$ and $900 \mathrm{~mL}$ of Acetate Buffer $\mathrm{pH} 4.5$ was used as the dissolution medium. Samples $(10 \mathrm{ml})$ were collected at predetermined time intervals $(1,2,3,4,6,8,10,12,16,20$ and $24 \mathrm{hrs})$ and replaced with equal volume of fresh medium, filtered through a $0.45 \mu \mathrm{m}$ filter and analyzed with a UV-Visible spectrophotometer (Shimadzu UV-1700 UV/Vis double beam spectrophotometer) at 274nm. Drug concentration was calculated from a standard calibration plot and expressed as cumulative \% drug dissolved.

\section{Surface morphology}

To investigate the change in the membrane structure, surface of coated tablets (both before and after dissolution studies) was studied using Scanning Electron microscopy (SEM).When tablet is suspended in the dissolution medium, the coating membrane imbibes water thereby forming pores by leaching the water-soluble pore formers. The changes in the appearance of coating membrane of SCOP during the dissolution process were studied using SEM.

\begin{tabular}{ccccc}
\hline Batch No. & CA:PEG & $\begin{array}{c}\text { \% Weight } \\
\text { Gain }\end{array}$ & $\begin{array}{c}\text { Orifice } \\
\text { Diameter }\end{array}$ & $\begin{array}{c}\text { No. of } \\
\text { Orifice }\end{array}$ \\
\hline B31 & $6.5: 3.5$ & 10 & 850 & 1 \\
\hline B32 & $7.0: 3.0$ & 10 & 850 & 1 \\
B33 & $7.5: 2.5$ & 10 & 850 & 1 \\
B34 & $8.0: 2.0$ & 10 & 850 & 1 \\
B35 & $6.5: 3.5$ & 10 & 350 & 1 \\
B36 & $6.5: 3.5$ & 10 & 550 & 1 \\
B37 & $6.5: 3.5$ & 10 & 650 & 1 \\
B38 & $6.5: 3.5$ & 8 & 850 & 1 \\
\hline
\end{tabular}

Table 2: Coating membrane composition for SCOP

\section{Burst strength}

Burst strength of the exhausted shells ( $n=6)$, after $24 \mathrm{~h}$ of dissolution, was determined to assure that the tablets would maintain their integrity in the GIT. Burst strength was determined, as the force required to break/rupture the shells after dissolution studies. The texture analyzer (Brookfield's Texture Analyzer - QTS) with a $5 \mathrm{~kg}$ load cell and $25 \mathrm{~mm}$ aluminum cylindrical probe was utilized for this purpose. Test speed of $0.8 \mathrm{~mm} / \mathrm{s}$ was selected and the distance moved was set at $6 \mathrm{~mm}$.

\section{Accelerated stability studies}

Optimized formulation of SCOP was packed in aluminum strips laminated with PVC. According to ICH guideline, the packed formulations were stored in stability chambers (Cintex humidity oven; Cintex Industrial Corporation, Dadar, Mumbai) maintained at $40^{\circ} \mathrm{C}$ and $75 \%$ relative humidity for 3 months. The samples were withdrawn each month and analysed for drug content and drug release rate using UV spectrophotometer.

\section{Results \& Discussion \\ Drug-excipients compatibility study}

As shown in (Figures $1 \mathrm{~A}$ to $1 \mathrm{~F}$ ), DSC thermograms of individual excipients, SET, Natrosol 250HX and Neosorb P 30/60 DC and 1:1 of SET:Natrosol 250HX and SET:Neosorb P 30/60 DC and drug with excipients were obtained and compared. DSC thermogram of SET (Form II) (Figure 1A-1F) show a very small endotherm at $188.44{ }^{\circ} \mathrm{C}$ $(\Delta \mathrm{H}=7.75 \mathrm{~J} / \mathrm{g})$ with onset temperature at about $181.74{ }^{\circ} \mathrm{C}$, which corresponds to a solid - solid transition to Form III $[23,24]$. This event is followed by melting of Form III with an onset at $247.44{ }^{\circ} \mathrm{C}$, sharp peak at $250.93{ }^{\circ} \mathrm{C}(\Delta \mathrm{H}=67.66 \mathrm{~J} / \mathrm{g})$ and recovery at $255.56{ }^{\circ} \mathrm{C}$, which is in the range of $246-251{ }^{\circ} \mathrm{C}$. Third peak of thermogram at 295.86 may be degradation of SET. So, it can be concluded that transition on the graph is the melting point of the SET [25].

Figure-1B and $1 \mathrm{C}$ show peak at $237.01^{\circ} \mathrm{C}(\Delta \mathrm{H}=12.48 \mathrm{~J} / \mathrm{g})$ with onset 227.57 and recovery at $243.06{ }^{\circ} \mathrm{C}$ and peak at $103.77{ }^{\circ} \mathrm{C}$ $(\Delta \mathrm{H}=113.39 \mathrm{~J} / \mathrm{g})$ with onset at $95.25^{\circ} \mathrm{C}$ and recovery at $110.92^{\circ} \mathrm{C}$ for Natrosol 250HX and Neosorb P 30/60 DC, respectively.

Thermogram of SET and Natrosol 250HX mixture (Figure 1D) shows peak for SET with an onset $252.37^{\circ} \mathrm{C}$, a maxima at $253.39{ }^{\circ} \mathrm{C}$ $(\Delta \mathrm{H}=69.25 \mathrm{~J} / \mathrm{g})$ and recovery at $263.01^{\circ} \mathrm{C}$. Thermogram of SET alone shows sharp peak at $250.93{ }^{\circ} \mathrm{C}(\Delta \mathrm{H}=67.66 \mathrm{~J} / \mathrm{g})$, onset at $247.74{ }^{\circ} \mathrm{C}$ and recovery at $255.56^{\circ} \mathrm{C}$, which indicate that there was no change in peak maxima and enthalpy and hence no interaction between drug and polymer.

Thermogram of SET and Neosorb P 30/60 DC (Figure-1E) show peak for SET with an onset $246.72^{\circ} \mathrm{C}$, a maxima at $253.98{ }^{\circ} \mathrm{C}$ $(\Delta \mathrm{H}=66.26 \mathrm{~J} / \mathrm{g})$ and recovery at $255.52^{\circ} \mathrm{C}$. Thermogram of SET alone shows sharp peak at $250.93{ }^{\circ} \mathrm{C}(\Delta \mathrm{H}=67.66 \mathrm{~J} / \mathrm{g})$, onset $247.74{ }^{\circ} \mathrm{C}$ and recovery at $255.56{ }^{\circ} \mathrm{C}$, which indicate that there was no changes in peak maxima and enthalpy and hence no interaction between drug and osmogent. 
Patel et al. Journal of Pharmaceutical Technology \& Drug Research 2012, http://www.hoajonline.com/journals/pdf/2050-120X-1-1.pdf

doa: $10.7243 / 2050-120 \mathrm{X}-1-1$

Figure 1A: DSC curve of SET

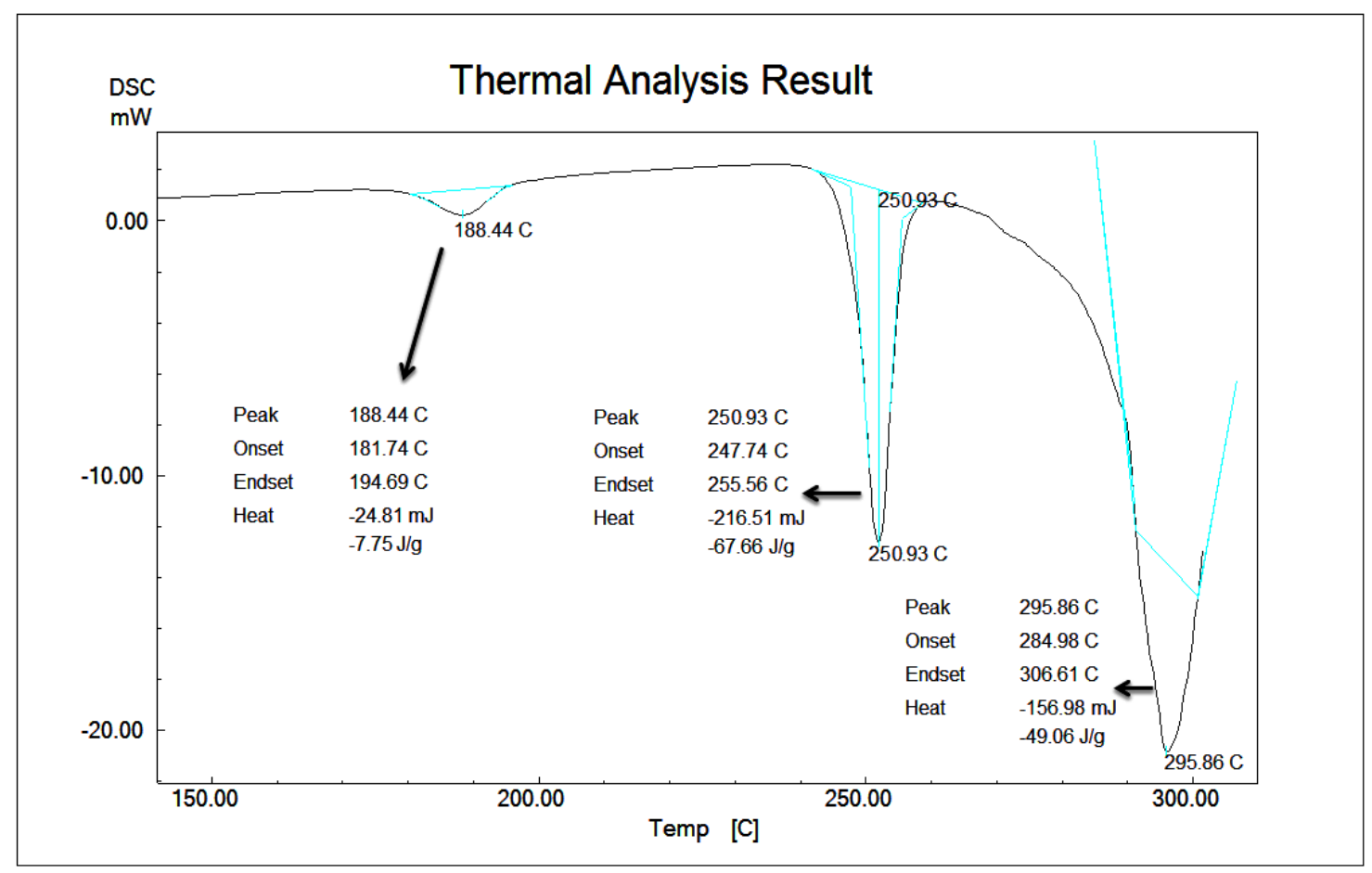

Figure 1B: DSC curve of Natrosol $250 \mathrm{HX}$

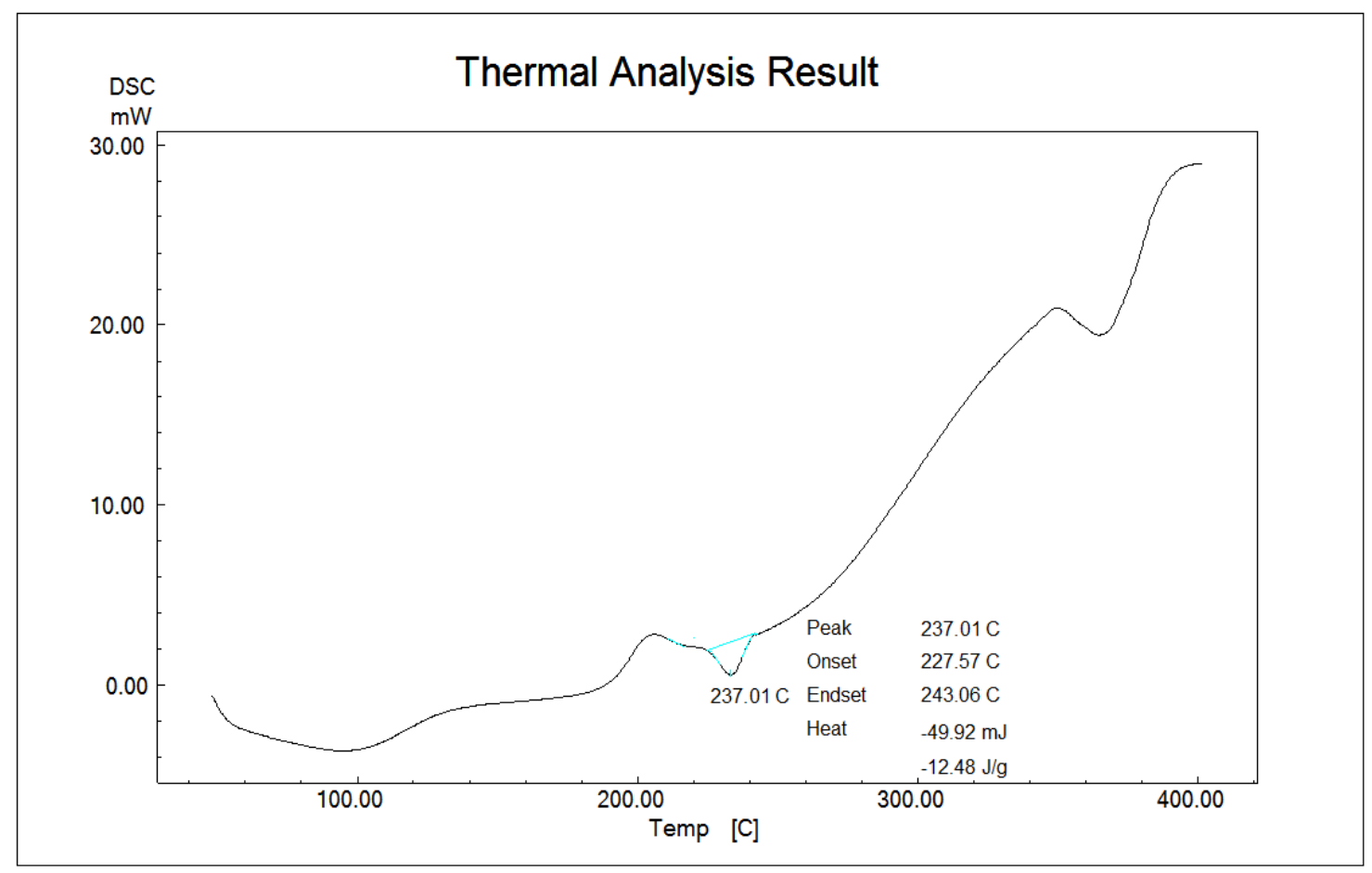

4 
Figure 1C: DSC curve of Neosorb P 30/60 DC

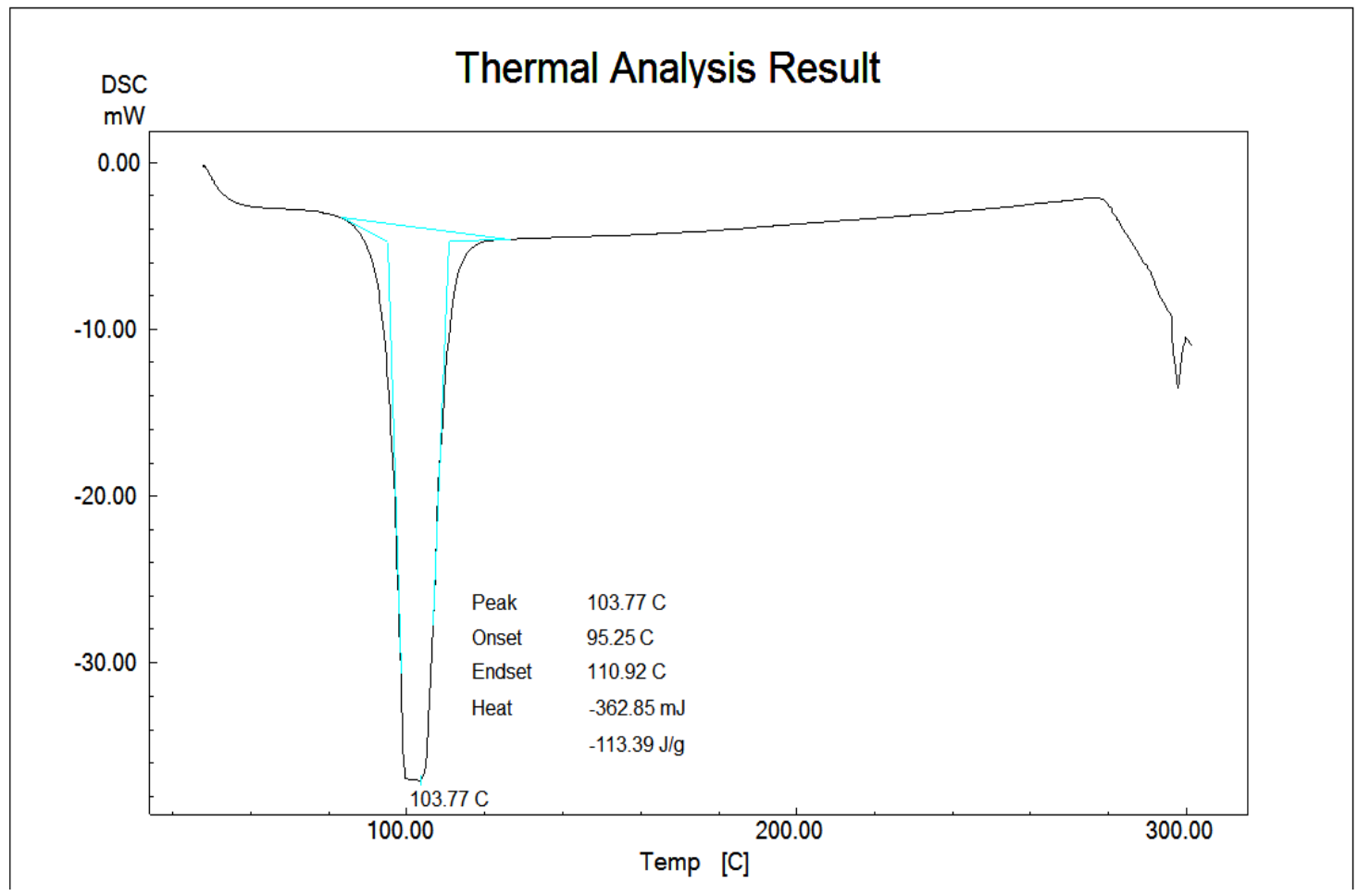

Figure 1D: DSC curve of SET + Natrosol 250 HX




Figure 1E: DSC curve of SET + Neosorb P 30/60 DC

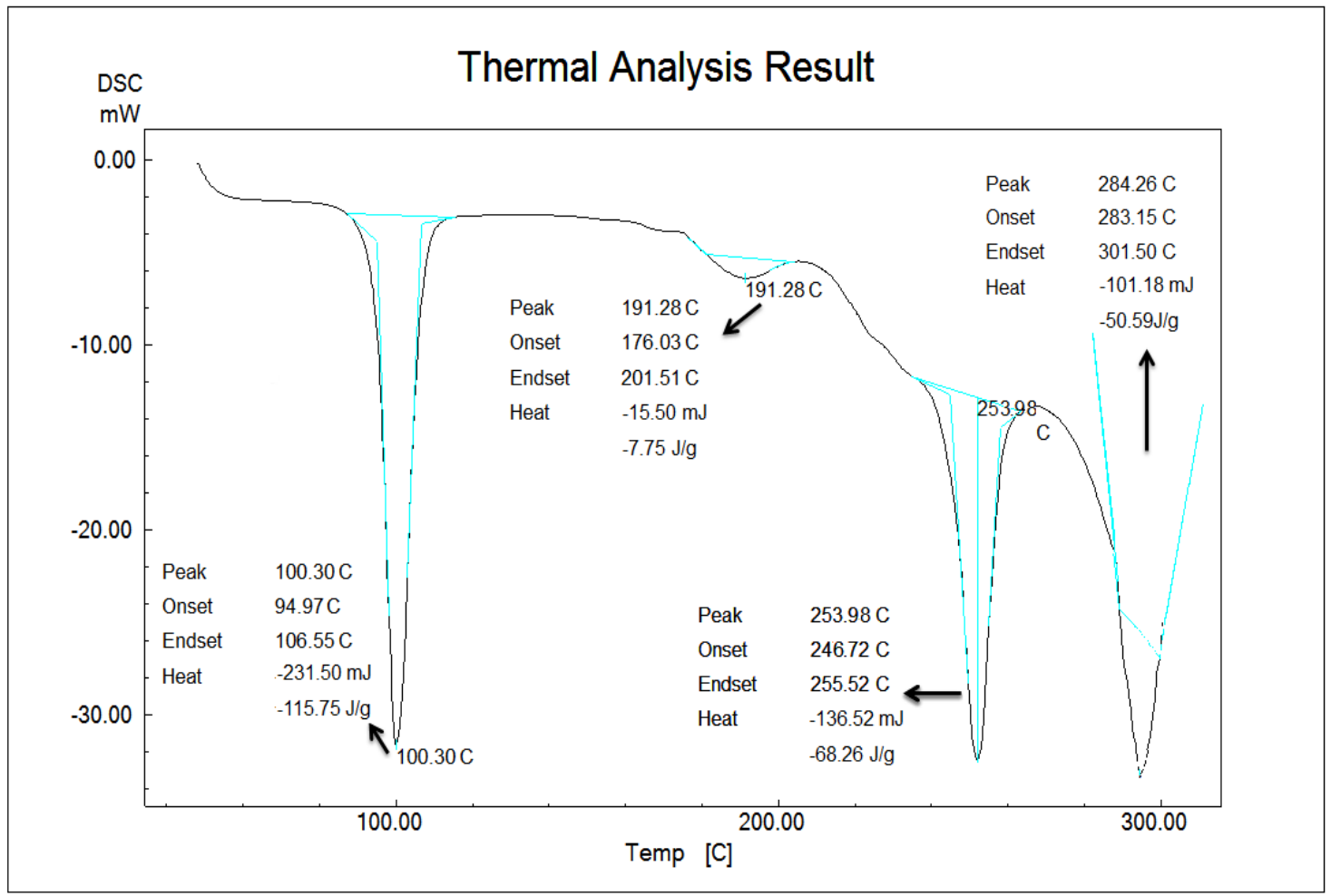

Figure 1F: DSC curve of SET + Excipients

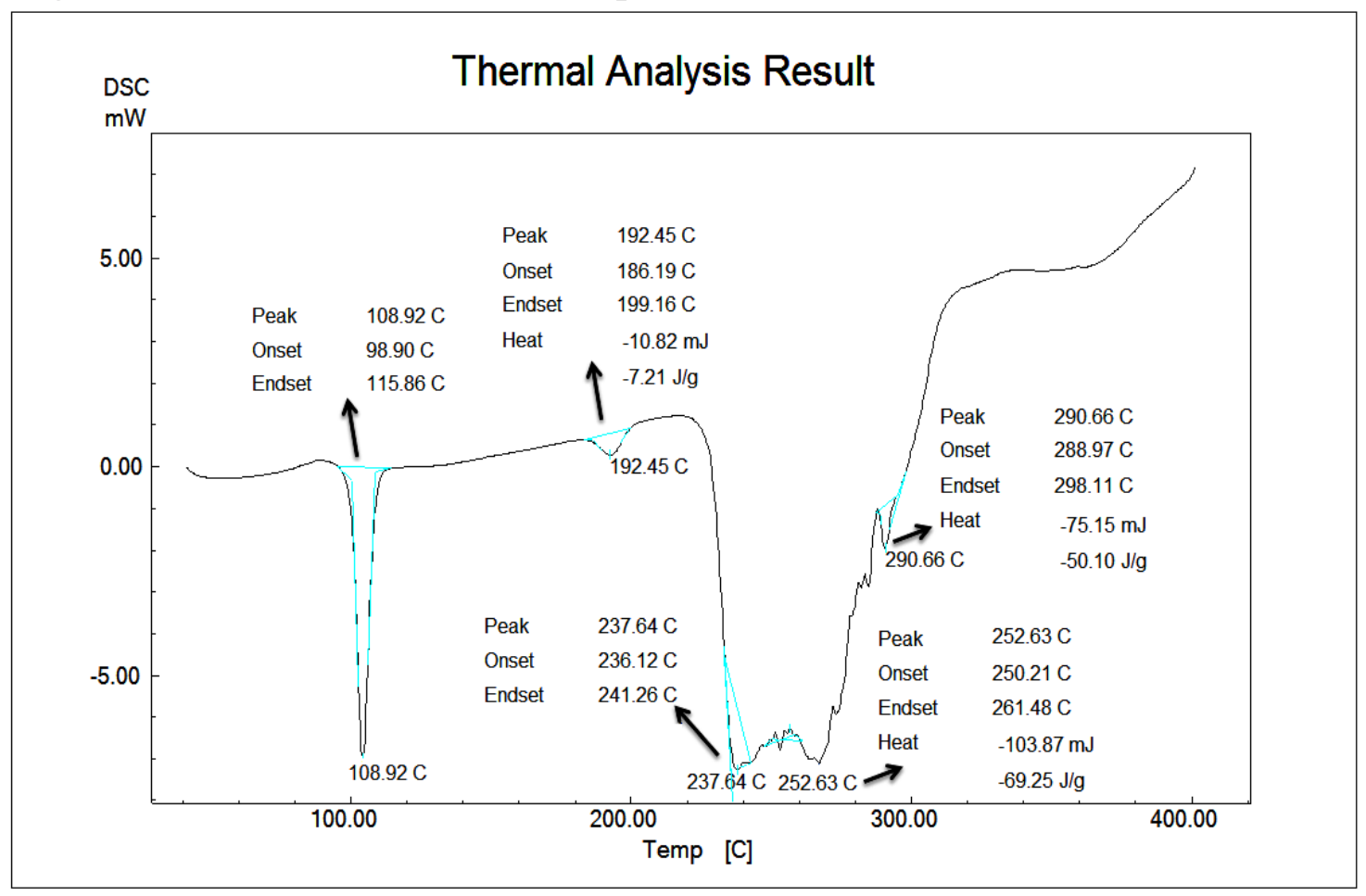


Figure $1 \mathrm{~F}$ show thermogram of SET with an excipients: 1) Natrosol $250 H X, 2)$ Neosorb P 30/60 DC, 3) Klucel EXF and 4) SLS show no significant change in peak maxima at $252.63(\Delta \mathrm{H}=69.25 \mathrm{~J} / \mathrm{g})$, onset at 250.21 and recovery at 261.48 in comparison with Figure $1 \mathrm{~A}$ of SET alone having at $250.93{ }^{\circ} \mathrm{C}(\Delta \mathrm{H}=67.66 \mathrm{~J} / \mathrm{g})$, onset $247.74{ }^{\circ} \mathrm{C}$ and recovery at $255.56{ }^{\circ} \mathrm{C}$. No significant changes in enthalpy, peak onset, peak maxima and recovery peak were noted in all these cases indicating compatibility of SET with used excipients.

\section{Drug estimation}

A linear correlation was obtained between peak areas versus concentration of SET in the range of 100 to $200 \mu \mathrm{g} / \mathrm{ml}$. The $\%$ recovery was found to be varying from $98.43 \pm 0.491$ to $101.91 \pm 0.6148$ indicate that proposed method was accurate. Each measurement represented the average of three replicates. The slope of regression line, $y$-intercept and correlation coefficient were $0.0029,0.0331$ and 0.9997 respectively.

\section{Formulation development and optimization of core tablet Influence of water swellable polymer}

In this study, different core formulations were made using $10 \% \mathrm{w} / \mathrm{w}$ of core weight of Natrosol 250HX, Polyox WSR Coagulant, Xanthan Gum, Klucel HF and HPMC K4M. Q 24 were $43.24 \%, 38.12 \%$ and $39.80 \%$ for the osmotic device containing Xanthan Gum, Klucel HF and HPMC $\mathrm{K} 4 \mathrm{M}$, respectively. These polymers do not appear to be different from the control $\left(Q_{24}\right.$ was $\left.34.30 \%\right)$, which has no water swellable polymer; further more $\mathrm{RSQ}_{\text {ZERO12 }}$ for formulation containing Klucel HF and HPMC K4M were 0.8506 and 0.9113 respectively, which indicate that these polymer did not show good release profile. However, hydroxy ethyl cellulose (Natrosol 250HX) and PolyoxWSR Coagulant appears to be quite effective. These two polymer show good release profile. For formulation containing 10\% core weight of Natrosol 250HX and Polyox WSR Coagulant, $\mathrm{Q}_{24}$ were $70.30 \%$ and $59.67 \%, \mathrm{RSQ}_{\text {ZERO } 12}$ were 0.9899 and 0.9852 and $\mathrm{RR}_{12}$ were 10.88 and 8.38 , respectively. Figure 2 shows the effect of water swellable polymers on drug release.

However, shortest lag time $\left(T_{L}: 1.12 \mathrm{~h}\right)$, good release rate $\left(R_{12}: 10.88\right)$ and amount of drug release within $12 \mathrm{~h}\left(\mathrm{Q}_{12}: 59.34\right)$ demonstrate that Natrosol $250 \mathrm{HX}$ is the first choice for SCOP system to obtain zero order release and reasonable amount of drug release for a period of $24 \mathrm{~h}$.

At a given extrusion pressure, the extrusion rate typically slows with increased viscosity. Applicants have surprisingly determined that high molecular weight hydroxyethyl cellulose (Natrosol 250HX) in combination with the drug particles form high viscosity solutions with water but are still capable of being extruded from the tablets with a relatively low force. The effectiveness of HEC is possibly related to its rheological properties and rate of hydration [26]. Also, the pressure produced during swelling did not lead to rupture of the system. The results also showed that uniform rate of swelling of the polymer ensured that the drug is released at a relatively constant rate $\left(\mathrm{RSQ}_{\text {ZERO 12 }}:\right.$ 0.9899). According to observed results, Natrosol $250 \mathrm{HX}$ was adopted for further investigation.

\section{Influence of different osmotic agent}

A number of potential osmotic agents having different osmotic pressures were examined. Figure 3 shows release profiles of formulations containing Mannogem, Neosorb P30/60 DC, Pharmaburst 500 and Xylitab as osmotically active agents. The figure indicates that the highest $Q_{12}$ and shortest $T_{L}$ were obtained from the devices containing NeosorbP30/60 DC $\left(Q_{12}: 56.17\right.$ and $T_{L}$ : 1.15h).Comparing $\mathrm{RSQ}_{\text {ZERO } 12}$ values of release data from osmotic devices containing 262 mg of Mannogem, Neosorb P30/60 DC, Pharmaburst 500 and Xylitab showed the highest $\mathrm{RSQ}_{\text {ZERO 12 }}$ for the device containing Neosorb P30/60 DC $\left(\mathrm{RSQ}_{\text {ZERO } 12}\right.$ was 0.9950, 0.9886, 0.9205 and 0.9850 for Neosorb P30/60 DC, Xylitab, Mannogem and Pharmaburst 500, respectively). $Q_{24}$ for Xylitab was slightly greater than Neosorb P30/60 DC. However, shortest $T_{L}$ and higher $\mathrm{Q}_{12^{\prime}} \mathrm{RR}_{12}$ and $\mathrm{RSQ}_{\text {ZERO 12 }}$ of Neosorb P30/60 DC demonstrate that Neosorb $\mathrm{P} 30 / 60 \mathrm{DC}$ is the first choice for SCOP system to obtain zero order release and reasonable amount of drug release for a period of $24 \mathrm{~h}$. In other words, osmotic pumps containing Neosorb P30/60 DC as the osmotic agent followed zero order release pattern. The results also showed that the presence of Neosorb P30/60 DC markedly diminished $T_{L}$ of the drug release from osmotic system (1.15 h for Neosorb P30/60 DC versus 1.3h, 3h and 3.3 h for Xylitab, Mannogem and Pharmaburst 500, respectively, $p<0.05)$. The lowest $Q_{24}(54.64 \%)$ and longest $T_{L}(3.3 \mathrm{~h})$ were related to formulation which contained Pharmaburst 500 as osmotic agent. The lowest release rate for the devices containing Pharmaburst 500 could be due to a low osmotic activity [27]. Therefore, formulation containing $262 \mathrm{mg}$ of Neosorb P 30/60 DC was adopted for further investigation.

\section{Influence of solubilizer}

There are a variety of factors to consider when choosing an appropriate organic acid [28] for use as a solubilizer with SET. An organic acid meeting such criteria is citric acid, which has very high water solubility ( $>2000 \mathrm{mg} / \mathrm{ml}$ ), high ratio of equivalents of acid per gram $(15.6 \mathrm{mEq} / \mathrm{g})$ and high osmotic pressure.

Figure 4 show release profile of formulation containing different concentration of citric acid. $Q_{12}$ were $61.68 \%, 62.45 \%, 62.17 \%, 68.42 \%$, $69.98 \%$ and $73.42 \%$ for $0 \%, 3 \%, 6 \%, 9 \%, 12 \%$ and $15 \%$ of citric acid of core weight. It indicates that drug release increased as amount of citric acid was increased.

$\mathrm{T}_{80 \%}$ for formulation containing $0,3,6,9,12$ and $15 \%$ of citric acid were $24,22,22,18,18$ and $16 \mathrm{~h}$. These result indicate that amount of citric acid had a pronounced effect on release profile of SET from osmotic systems. However, $T_{L}$ and $R_{12}$ were relatively same for formulation containing 9,12 and $15 \%$ of citric acid $\left(T_{L}: 0.45\right.$ for all three formulations and $R_{12}: 12.77 \mathrm{mg} / \mathrm{h}, 13.06 \mathrm{mg} / \mathrm{h}$ and $13.71 \mathrm{mg} / \mathrm{h}$, respectively $(p=0.03)$. Because of shortest $T_{80 \%}(16 \mathrm{~h})$ and higher correlation coefficient of zero-order kinetic $\left(\mathrm{RSQ}_{\text {ZERO 12 }}: 0.9948\right)$ of the formulation containing $15 \%$ of citric acid in comparison with the tablets containing $9 \%$ and $12 \%$ of citric acid $\left(T_{L}: 18 \mathrm{~h}\right.$ and $18 \mathrm{~h}$ and $\mathrm{RSQ}_{\text {ZERO 12 }}: 0.9913$ and 0.9907 , respectively), was adopted as a suitable formulation and further investigations were carried out 


\section{Figure 2: Influence of hydrophilic polymer on in vitro SET release}

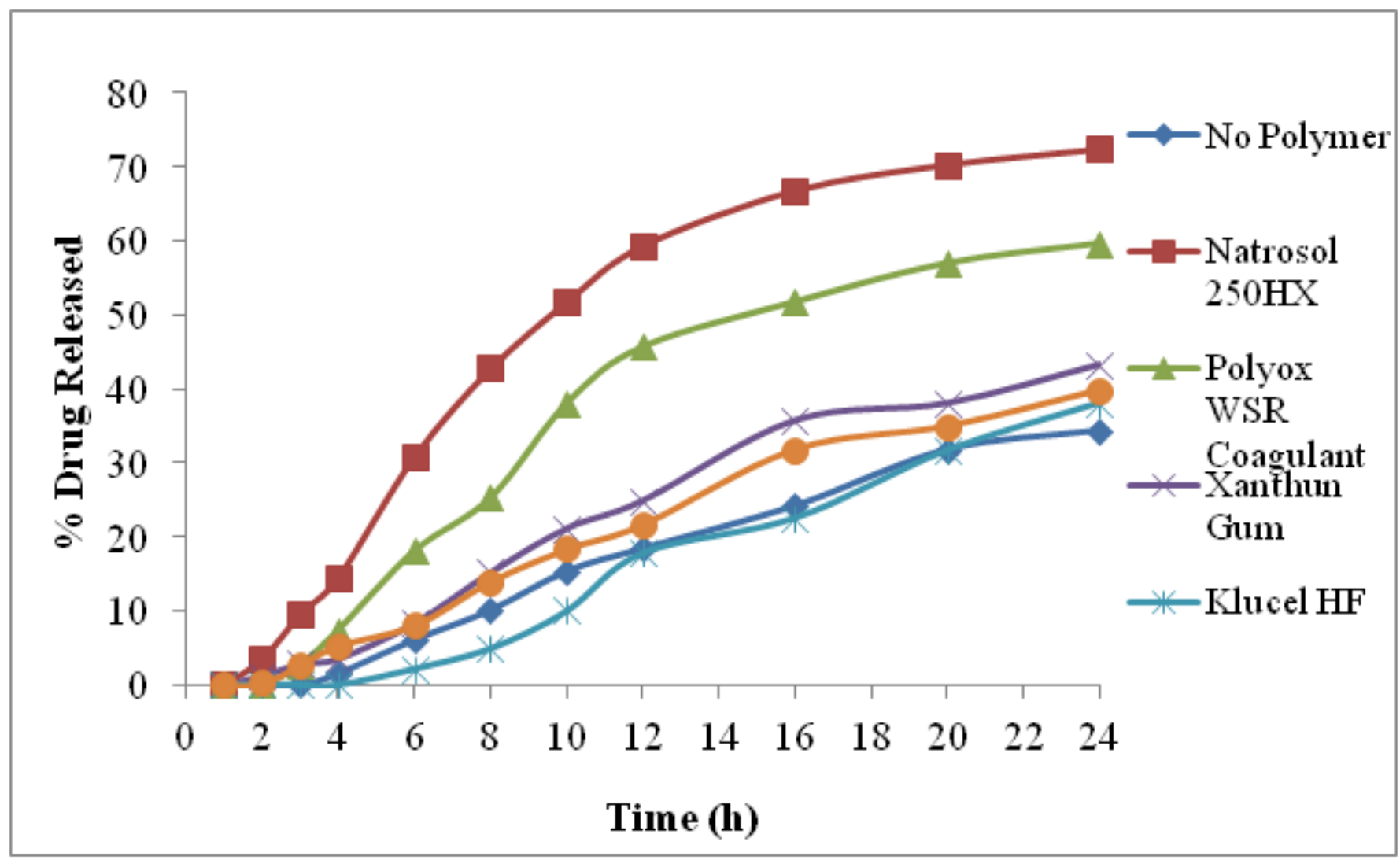

Figure 3: Influence of osmogent on in vitro SET release

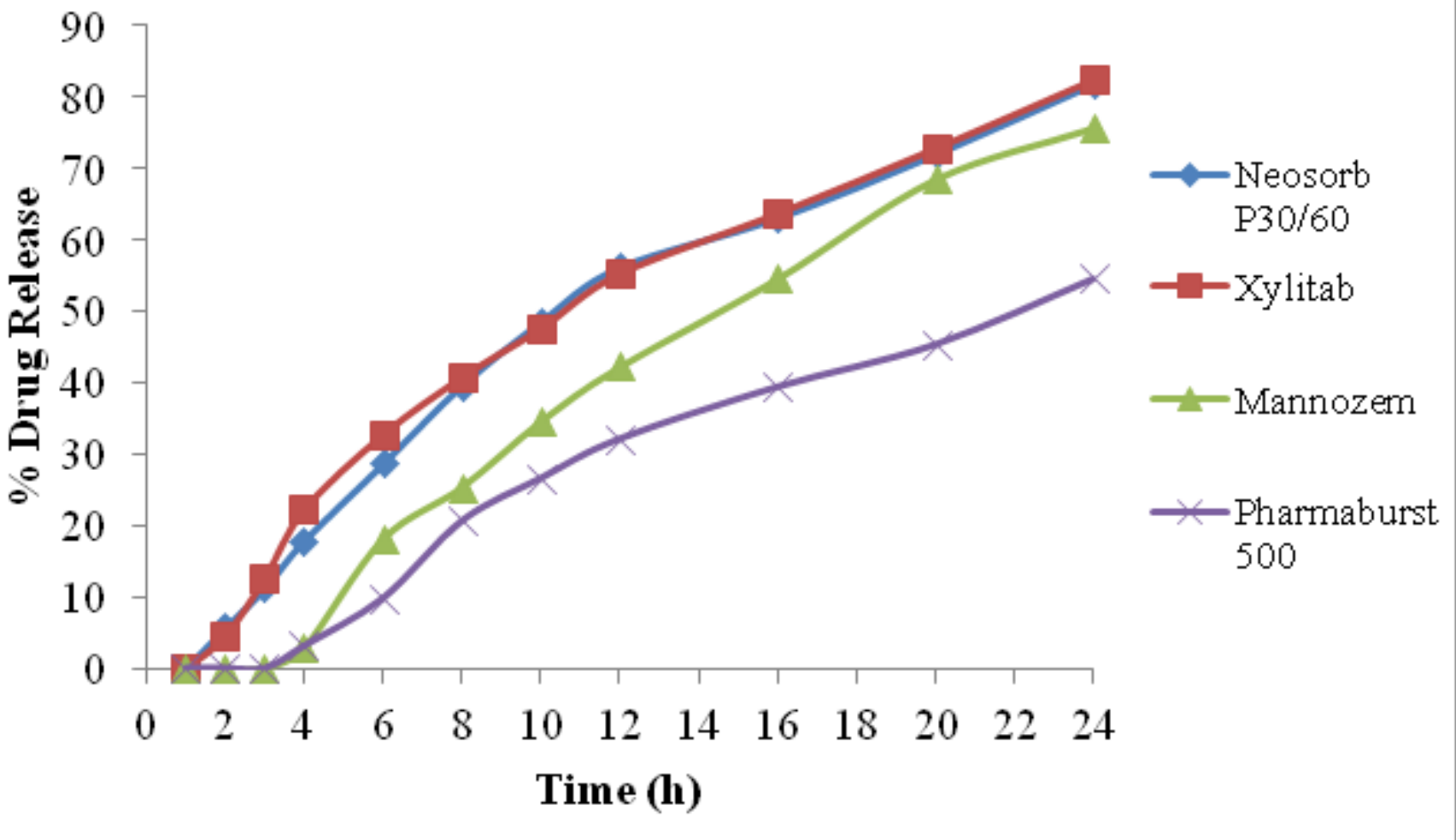


Figure 4: Influence of different concentration of citric acid on in vitro SET release



Figure 5: Release profile of SET from formulation containing different concentration of PEG 4000 in the SPM formulation

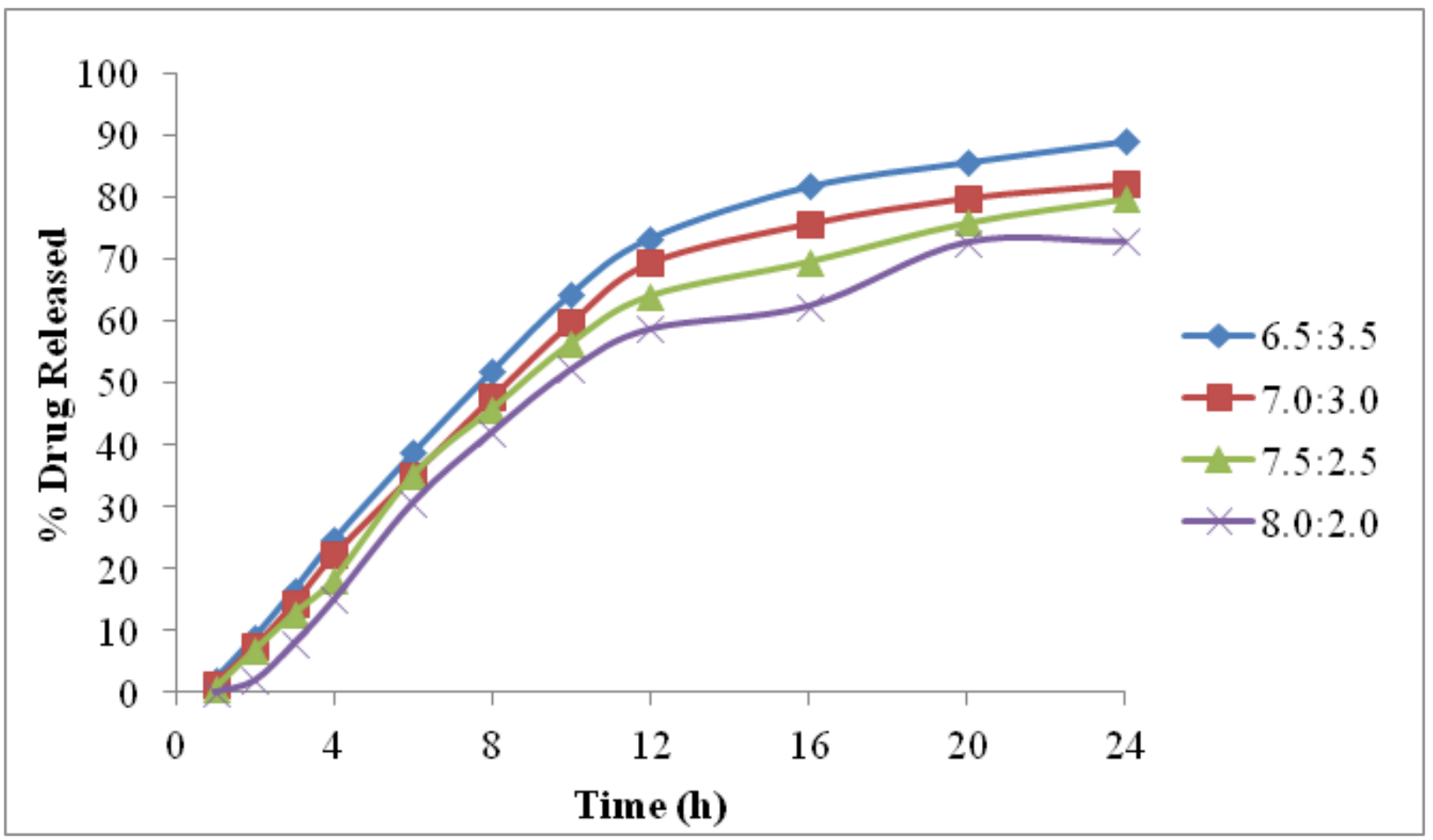




\section{Figure 6: Release profile of SET from osmotic device with different SPM thicknesses}

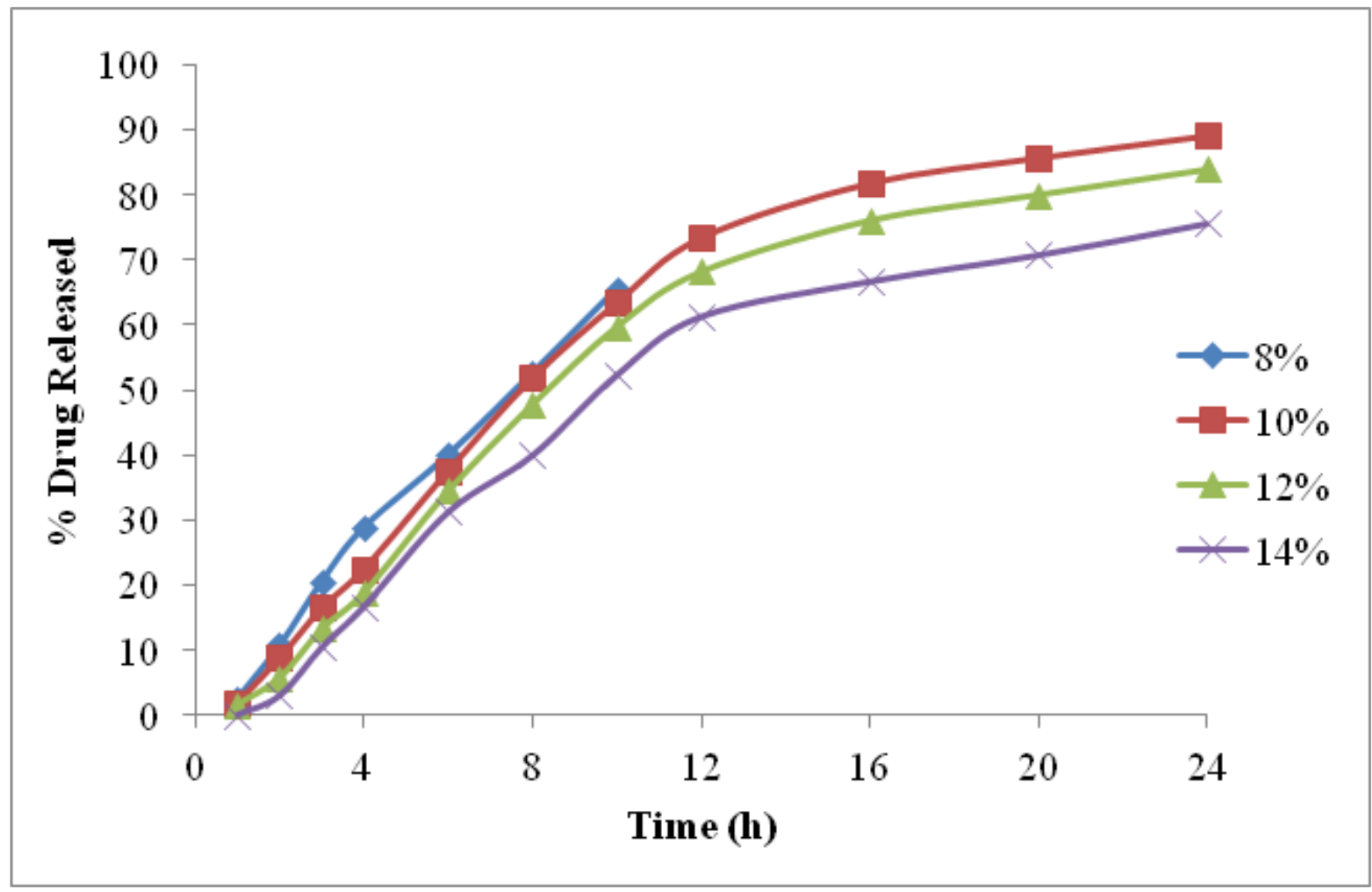

on this formulation to examine the effect of coating parameters, mainly the number and size of orifice, thickness of coating and the concentration of plasticizers.

\section{Influence of coating and drilling}

Based on the above results, optimized tablet formulation B4 was adopted in the following study. The membrane was also an important factor for the release profile of SCOP. Plasticizers are added to modify the physical properties and improve film-forming characteristics of polymers. As plasticizers will also affect the permeability of polymer films it is important to investigate the effect of plasticizer on the release rate of drug from osmotic devices. As PEG is a hydrophilic plasticizer, it could be leached easily and left behind wholly porous structure, which increases membrane permeability and drug release rate. Water permeation through the coating is affected by the cellulose acetate: PEG (CA: PEG) ratio used in the formulation of the coating solution. To study the influence of amount of PEG on drug release, the CA membranes were plasticized with different ratio of PEG. Figure 5 shows the release profiles of formulations containing different amounts of plasticizer. $Q_{12}$ for membrane containing CA: PEG ratio of $6.5: 3.5,7.0: 3.0,7.5: 2.5$ and $8.0: 2.0$ were $73.42 \%, 66.45 \%, 62.1 \%$ and $58.63 \%$ respectively. Results shows that increase of PEG level led to an increase of drug release rate. The more PEG incorporated into the CA membrane, the more void space formed after leaching and, in turn, the higher the permeability of the membrane, the higher the drug release rate obtained.

PEG 4000, which was added to the coating formulation as hydrophilic plasticizer, can increase the hydrophilicity of semipermeable membrane (SPM) and increase the rate of water penetration across the membrane and thus, decrease lag time of osmotic systems ( $T_{L}$ were $0.3,0.3,0.45$ and $2.15 \mathrm{~h}$ for membrane containing CA:PEG ratio of $6.5: 3.5,7: 3,7.5: 2.5$ and $8: 2$, respectively). Similar results were reported about relationship between water imbition and $\mathrm{T}_{80 \%} \cdot \mathrm{T}_{80 \%}$ for membrane containing CA: PEG ratio of6.5:3.5, 7:3 and 7.5:2.5 were15, 20 and $24 \mathrm{~h}$, respectively. On the contrary, $80 \%$ of drug release was not observed with membrane containing CA: PEG ratio of 8.0:2.0. It can be concluded that a good hydrophilic/lipophilic balance in SPM structure is required to achieve desirable release profile with zero order kinetics. It can be predicted from the figure that membranes containing CA: PEG in ratio of 6.5:3.5 is optimum in SPM formulation for SCOP to obtain zero order release device.

The most straightforward method to modify the drug-release profile of SCOP formulation is to vary the coating weight. Proper selection and optimization of the SPM thickness is one of the best 
Figure 7: Release profiles of SET from osmotic devices with different orifice size

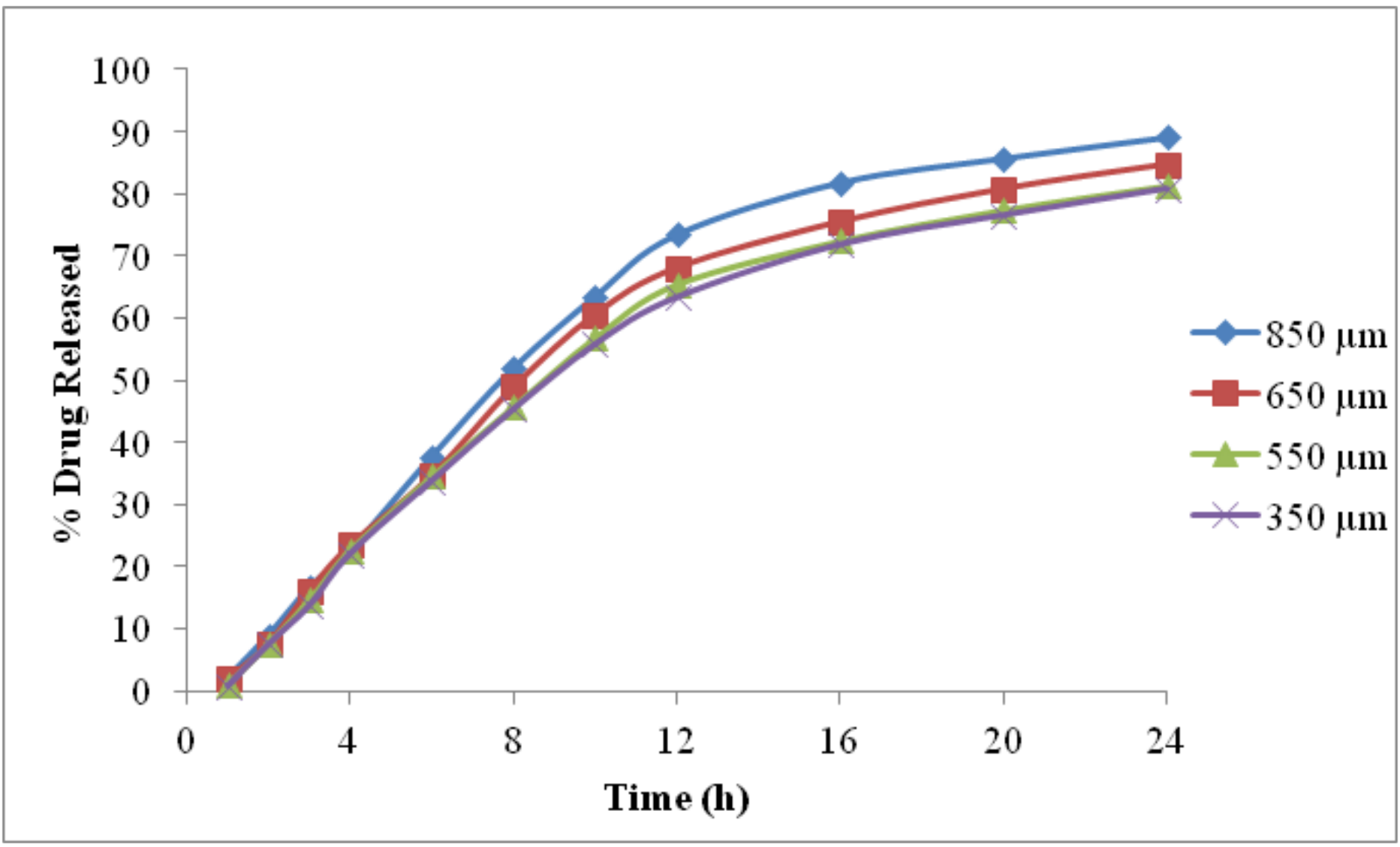

ways to achieve a constant release rate of drugs from osmotic tablets. Figure 6 represents the release profiles of osmotic devices formulated with different SPM thicknesses. The optimal tablets were coated to obtain weight gain of $8 \%, 10 \% 12 \%$ and $14 \%$ of core weight, respectively (CA: PEG ratio, i.e. 6.5:3.5 was constant for all formulation). SPM having $8 \%$ of weight gain cracked and disintegrated after the exposure of the tablet to the dissolution medium.

Figure 6 shows that increasing the membrane thickness increased resistance of the membrane to diffusion of dissolution medium followed by a reduction in the liquefaction rate of the tablet core which, ultimately, reduced drug release rate from osmotic devices. Results shows that increasing coating weight from 10\% to $14 \%$ increased lag time and decreased $Q_{24}$ significantly ( $T_{L}$ was 0.3 , 0.45 and $1.3 \mathrm{~h}$ and $\mathrm{Q}_{24}$ was $89.08,83.92$ and 75.68 for formulation containing 10,12 and $14 \%$ of coating weight, respectively, $\mathrm{p}<0.05$ ). Evaluation of the parameters related to release kinetics revealed that the drug release from formulation having $10 \%$ coating weight of core weight followed zero order kinetics $\left(\mathrm{RSQ}_{\text {ZERO 12 }}\right.$ was 0.9965$)$ in comparison with formulation having $12 \%$ and $14 \%$ of coating weight of core weight ( $\mathrm{RSQ}_{\text {ZERO } 12}$ was 0.9950 and 0.9952 , respectively). These results demonstrated that SPM thickness should be optimized in order to ensure that the pressure produced during swelling does not lead to rupture of the system and also moisten the tablet in acceptable time range. Optimization of SPM thickness makes the osmotic system suitable in the case of release rate, release kinetics, lag time and other basic features.

Aperture diameter is one of the critical parameters that influences release rate, lag time and release kinetics of the osmotic drug delivery devices [29]. Thus, the size of delivery orifice must be optimized in order to control the drug release from osmotic systems. Figure 7 shows the release profiles of the drug from formulations with different aperture diameters. The orifice sizes of 350, 550, 650 and $850 \mu \mathrm{m}$ were drilled by mechanical driller on each side of the surface. No significant difference was observed between release rate of drug and the orifice diameter between 350 and $550 \mu \mathrm{m}$. However, results showed significant changes in some of the release parameters due to the change in orifice size of 350 and $550 \mu \mathrm{m}$. More specifically, $T_{L}$ and $\mathrm{RSQ}_{\text {ZERO 12 }}$ were remarkably improved $(\mathrm{p}<0.05)$ ) by increasing the aperture diameter from 350 to $550 \mu \mathrm{m}\left(\mathrm{T}_{\mathrm{L}}: 1\right.$ and $0.45 \mathrm{~h}$ while $\mathrm{RSQ}_{\text {ZERO 12 }}$ were 0.9923 and 0.9942 for orifice size of 350 and $550 \mu \mathrm{m}$ respectively). $Q_{24}$ was increased and lag times of the systems were decreased significantly as increasing the orifice diameter. $Q_{24}$ was increased from $80.84 \%$ with $350 \mu \mathrm{m}$ to $89.08 \%$ with $800 \mu \mathrm{m}$ orifice size. Lag time was decreased from $1 \mathrm{~h}$ to $0.3 \mathrm{~h}$ as the orifice size was increased from $350 \mu \mathrm{m}$ to $850 \mu \mathrm{m}(\mathrm{p}<0.05)$ respectively. These results indicate the importance of orifice diameter on the control of drug release from the SCOP. 
Among these, formulations having $850 \mu \mathrm{m}$ orifice size had highest $\mathrm{Q}_{24 \mathrm{~h}}$ and $\mathrm{T}_{80 \%}$ and shortest lag time $\left(\mathrm{Q}_{24 \mathrm{~h}}: 89.08 \%, \mathrm{~T}_{80 \%}: 16 \mathrm{~h}\right.$ and $\mathrm{T}_{\mathrm{L}}$ : $0.3 \mathrm{~h}, \mathrm{p}=0.02$ ). These results indicated that optimum aperture size in SCOP systems is considerably larger than ordinary Elementary Osmotic Pump (EOP) systems which are used for delivering high to moderately water-soluble drugs [29]. This difference probably originates from different mechanisms of drug release between these systems. EOPs generally released their drug content in soluble form [29] whereas SCOP releases the drug in soluble and in suspended solid particle forms concurrently.

\section{SEM study}

To investigate the change in the membrane structure during dissolution process, surface of coated tablets (both before and after dissolution studies) were studied using Scanning Electron Microscopy (SEM) [30]. The changes in the appearance of coating membrane of SCOP during the dissolution process are shown in Figure 8. As soon as the tablet is suspended in the dissolution medium, the coating membrane imbibes water thereby forming pores by leaching the water-soluble pore formers.

Figure $8 \mathrm{~A}$ shows membrane structure before dissolution; initially the surface of coated tablets was smooth before coming into contact with aqueous environment and coats appeared to be free of point defects. SEM of the micro porous structure of the membrane after dissolution is shown in Figure 8B. This significant change in porosity has resulted from the leaching of water-soluble additive, i.e. PEG 4000 , during dissolution and this increased the permeability of membrane.

\section{Burst strength}

After $24 \mathrm{hr}$ of dissolution studies, exhausted tablets were evaluated for burst strength to assure that the tablets maintain their integrity in GIT and do not lead to dose dumping. Figure 9 and 10 shows the dependence of burst strength of the exhausted shells on coat thickness and amount of plasticizer, respectively. Figure 9 show effect of coating thickness on burst strength. As coating weight of tablet increase, membrane becomes thicker, leading to increase in burst strength (Burst strength was $3724 \mathrm{~g}$ and $6913 \mathrm{~g}$ for $10 \%$ and $14 \%$ of coating weight, respectively, $\mathrm{p}<0.05$ ) another parameter that affects burst strength is the level of plasticizer of coating membrane. With the increase in level of PEG-4000, the membrane became more porous after exposure to water, leading to a decrease in its strength (Burst strength was $3724 \mathrm{~g}$ and $4901 \mathrm{~g}$ for 6.5:3.5 and 8.0:2.0 CA: PEG ratio, respectively). In all cases, the value is much higher than the mechanical destructive forces in GIT [31-32], thus assuring that the formulations can be expected to remain intact in GIT without any incidence of dose dumping. For optimized coating weight gain (10\%) and CA: PEG ratio (6.5:3.5), burst strength was $3724 \mathrm{~g}(37.24 \mathrm{~N})$, which indicate that SCOP remain intact in GIT.

\section{Accelerated stability studies}

An ethical drug manufacturer is committed to provide his consumers with drug products that are both efficacious and safe. This can only be ensured by instituting a program to study the stability of a product during its various phases of development and to use proper storage conditions and comply with the expiry period under those conditions.

With the recent trend toward globalization of manufacturing operations, it is imperative that the final product is sufficiently robust for marketing worldwide under a variety of climatic conditions, including tropical, subtropical, and temperate. The optimized formulation of SCOP containing SET was subjected to accelerated stability studies in an aluminum/aluminum strips to be the best protecting packaging materials, and it is used as packing material in the present study. Batch no. B4 was packed in an aluminum/ aluminum strip and subjected to short-term stability studies at 40 $\pm 2^{\circ} \mathrm{C}$ and $75 \pm 5 \%$ relative humidity for 90 days.

Samples withdrawn each month showed no significant change in physical appearance, drug content, and in vitro drug release characteristics. So, the formulations were found to be stable in terms of drug content and in vitro drug release after stability study, the in vitro drug release profiles of tablets are compared for various dissolution parameters shown in Table 3 for SET release. The values of different dissolution parameters showed that there was no significant difference between in vitro drug release profile of initial and after stability studies $(p<0.05)$.

\section{Conclusion}

The present study aimed to develop an oral osmotic system, SCOP which delivered the SET with controlled rate up to $24 \mathrm{~h}$. The core contains hydroxyethyl cellulose (Natrosol $250 \mathrm{HX}$ ), which serves to entrain the drug particles as they are extruded out a hole in the coating at one end of the tablet, and a sugar, which provides the osmotic driving force for water imbibition. The Single Core Osmotic Pump (SCOP) was simple to prepare, because there is no need for a push compartment, and is simpler with regard to orifice drilling compared with the push-pull osmotic tablet. Optimized formulation was found to be able to deliver drug at a rate of approximately zero order up to $12 \mathrm{~h}$. The rate of the drug release from these tablets increased with increased concentrations of the osmogent and the plasticizers but decreased with increased coating thickness. This study also revealed that it was possible to formulate a single layer osmotic controlled release tablet of water insoluble drug with large dose.

\begin{tabular}{cccccc}
\hline & $\begin{array}{c}\text { Assay of } \\
\text { SET }\end{array}$ & $\mathbf{T}_{\mathrm{Lh}}$ & $\mathbf{Q}_{12 \%}$ & $\mathbf{Q}_{24 \%}$ & $\mathbf{R S Q}_{\text {ZERO 12 }}$ \\
\hline Initial & $100 \pm 3.02$ & 1.12 & 59.34 & $70.30 \%$ & 0.9899 \\
After 30 days & $100 \pm 2.41$ & 1.11 & 58.89 & 70.01 & 0.9897 \\
After 60 days & $100 \pm 2.14$ & 1.12 & 58.49 & 69.89 & 0.9895 \\
& & & & & \\
After 90 days & $99 \pm 1.12$ & 1.01 & 58.11 & 69.45 & 0.9897 \\
\hline
\end{tabular}

Table 3: Comparison of dissolution parameter after stability study 


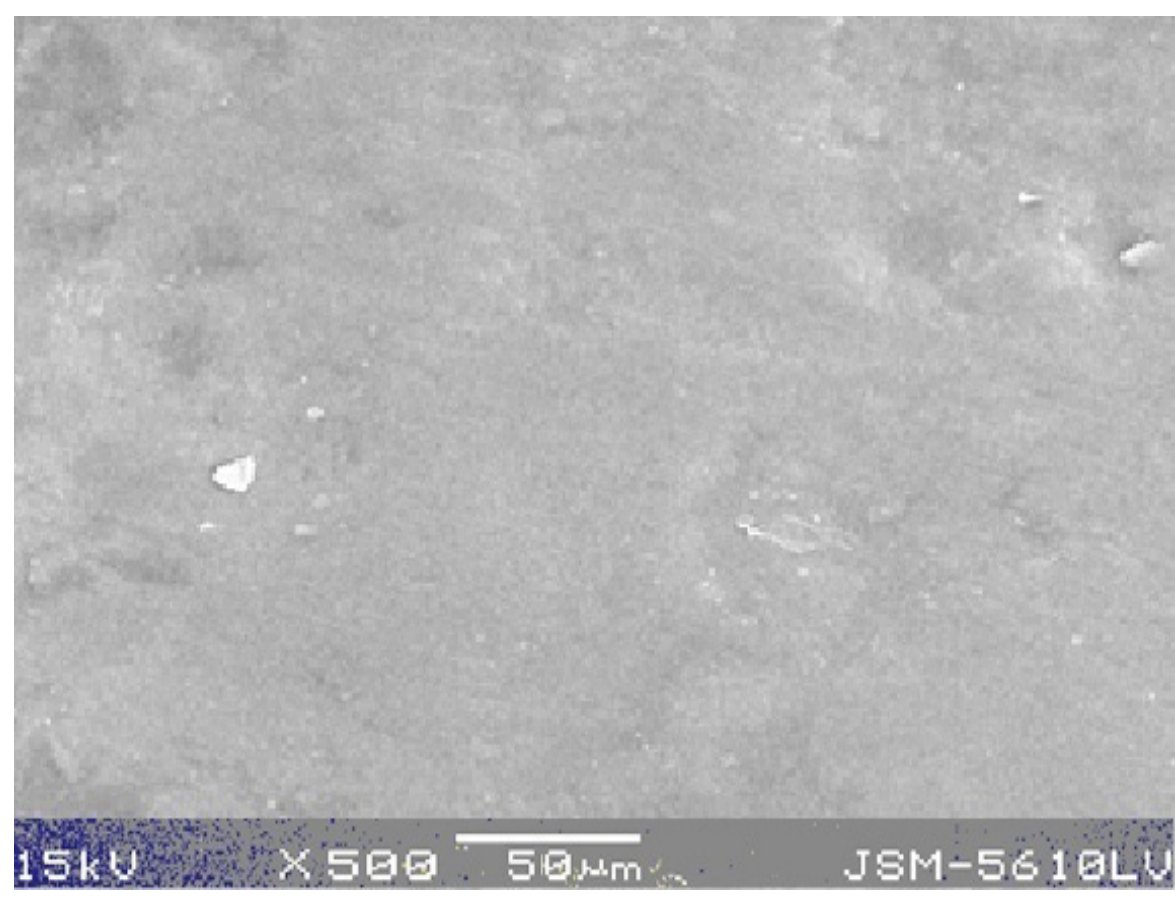

\section{A Before Dissolution}

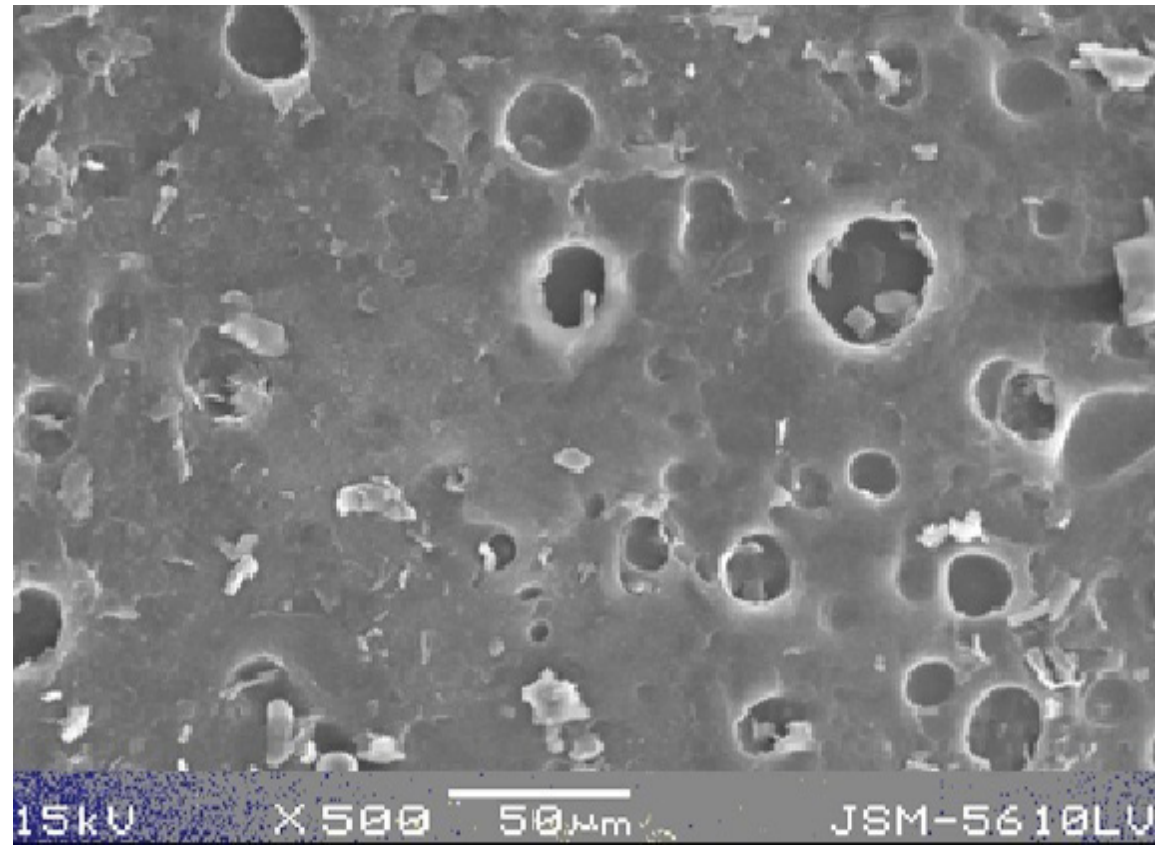

8B After Dissolution

Figure 8: Membrane structure of SCOP A) before and B) after dissolution 
Figure 9: Effect of coating weight on burst strength

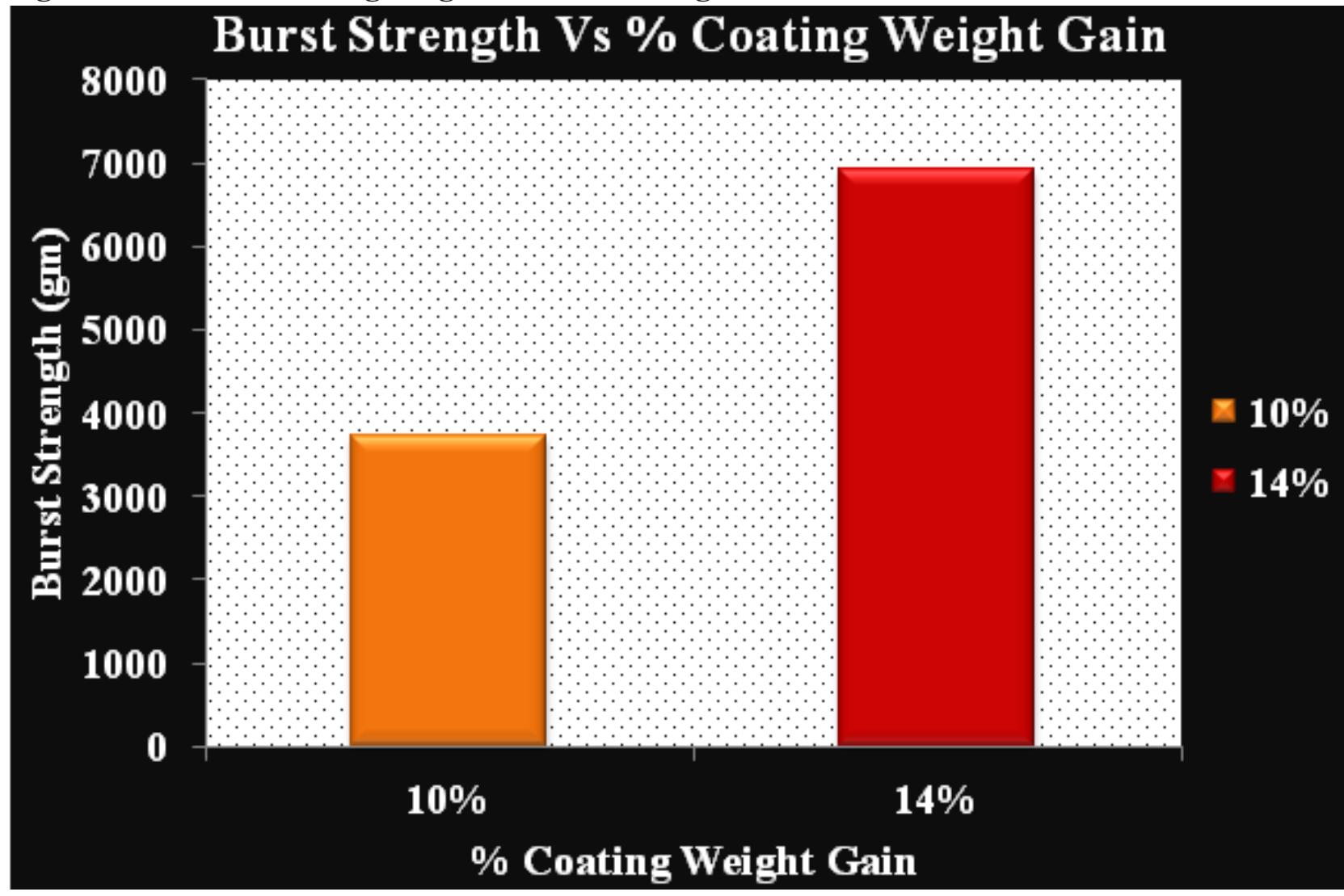

Figure 10: Effect of amount of plasticizer on burst strength

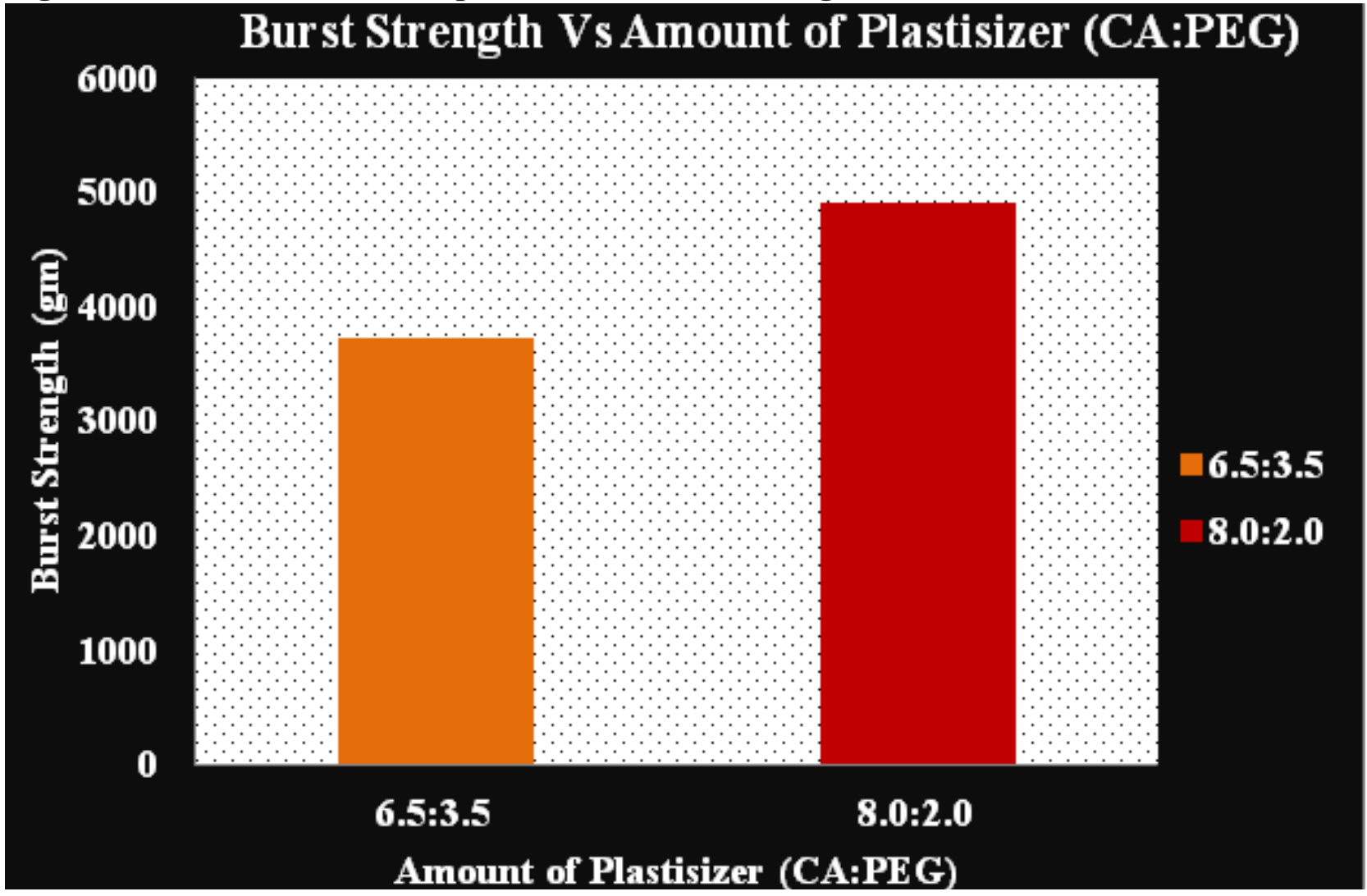




\section{Conflict of interest}

There is no interest of all authors in financial and personal relationship with any other people or any organization for publishing this research article or financial support for research work.

\section{Acknowledgement}

Authors want to hearty acknowledge all the listed companies for providing generous gifts for drug and other excipients.

\section{Article history}

Editor: S Pattnaik, Biju Pattnaik University of Technolgy, India Reviewer: Amusa S. Adebayo, Roosevelt University, USA. Received: 24-Dec-2011 Revised: 29-Feb-2012 Re-Revised: 06Mar-2012 Accepted: 07-Mar-2012 Published: 27-Mar-2012

\section{References}

1. Theeuwes, F: OROS osmotic system development. Drug Dev. Ind. Pharm.1983 9: 1331-135.

2. Zentner, GM, Rork, GS, Himmelstein K. J: The controlled porosity osmotic pump. J. Contr. Rel. 1985, 1: 269-282.

3. Bindschaedler C, GumyR ,Doelker E: Osmotically controlled drug delivery systems produced from organic solutions and aqueous dispersions of cellulose acetate. J. Contr. Rel. 1986, 4: 203-212.

4. Lindstedt $B$, Ragnarsson $G$, Hjartstam J: Osmotic pumping as a release mechanism for membrane coated drug formulations. Int. J. Pahrm. 1989, 56: 261-268.

5. Appel $L E$,Zentner $G M$ : Use of modified ethylcellulose lattices for microporous coating of osmotic tablets. Pharm. Res.1991, 8: 600-604.

6. Zentner M, McClelland GA, Sutton SC: Controlled porosity solubilityand resinmodulated osmotic delivery systems for release of diltiazem hydrochloride. J. Contr. Rel., 1991, 16: 237-244.

7. Okimoto K, Ohike A, Ibuki R, Aoki 0, Rajewski RA: Design and evaluation of an osmotic pump tablet (OPT) for chlorpromazine using (SBE). Pharm. Res., 1999, 5549-554.

8. Santus $\mathrm{G}$, Baker R W: Osmotic drug delivery: a review of the patent literature. J. Contr. Rel. 1995, 35: 1-21.

9. Theeuwes F: Elementary Osmotic Pump. J. Pharm. Sci., 1975, 64:1987-1991.

10. Khanna S C: Therapeutic system for sparingly soluble active ingredients. US Patent Number 4,992, 2781, 991.

11. Swanson D R, Barclay B L, Wong P S L, Theeuwes F:Nifedipine gastrointestinal therapeutic system. Ameri. J. Med., 1987, 83: 3-9.

12. Ayer $A D$, Wong $P S L$, Dosage form comprising solubility regulating member. US Patent 4,755,180,1988.

13. Magruder PR, Barclay B, Wong P, Theeuwes F:Composition comprising a therapeutic agent and a modulating agent. US Patent 4,851,229, 1989.

14. McClelland G. A., Sutton S C, Engle K,Zentner G M:The solubilitymodulated osmotic pump: In vitro-in vivo release of diltiazem hydrochloride. Pharm. Res. 1991, 8: 88-92.

15. KhannaSC, RuettimannT:Oral therapeutic system having systemic action. US Patent 4, 857, 336, 1987.

16. EX. Lu, Jiang ZQ,Zhang Q, Jiang G:A water-insoluble drug monolithic osmotic tablet system utilizing gum Arabic as an osmotic, suspending and expanding agent.J. Control. Release; 2003, 3: 375-382.

17. Liu X, Chen D., Zhang R, Evaluation of monolithic osmotic tablet system for nifedipine delivery in vitro and in vivo. Drug Dev. Ind. Pharm. 2003, 7: 813-819.

18. ShokriJ, AhmadiP, RashidiP, ShahsavariM, Rajabi-Siahboomi A, NokhodchiA:Swellable elementary osmotic pump (SEOP): an effective device for delivery of poorly water-soluble drugs. Eur. J. Pharm.
Biopharm. 2008, 2: 289-297.

19. Kenneth C., Waterman E LT Osmotic delivery system. US Patent 0161882 A1, 2003.

20. Anne B, Rebecca C, Osmotic delivery system. US Patent 0175346 A1, 2003.

21. William J, Hydrogel - Driven Layered Drug Dosage Form. US Patent 6,899,896 B2,2005

22. Mary Tanya Am Ende, Sertraline Salts and Sustained release Dosage Forms of Sertraline. US Patent 6,517,866 B1, 2003.

23. Rober J Sysko, Douglas JM,Sertraline Polymorph.US Patent: 5248699 , 1993.

24. Eduard Schwartz, Tamar Nidam, Anita Liberman, Marioara Mendelivici, Method for preparation of Sertraline HCl Polymorph. US Patent: 6600073 B1, 2003.

25. Schwartz Eduard, Nidam Tamar, Liberman Anita, Sertraline hydrochloride polymorphs. US Patent 7022881,2006.

26. Kenneth C. Waterman, Bruce C. MacDonald, Micheal C. Roy, Extrudable core system: Development of single layer osmotic controlled release tablet. J. of contr. Rel., 2009, 134(3): 201-206.

27. Biliote Anne Martine, Osmotic delivery system, European Patent No. EP 1469826 B1, 2006.

28. William Stern, Tenafly NJ, Nasal Calcitonin Formulation. US Patent No. RE40, 812, 2009.

29. Javad Shokari, Parinaz ahmadi, Parisa Rashidi, Swellable elementary osmotic pump (SEOP): An effective device for delivery of poorly water-soluble drugs. European J. of Pharm. and Biopharm., 2008, 68(2):289-297.

30. R B Patel, G N Patel, H R Patel, M M Patel, Inlay osmotic pump tablets containing metformin and glipizide. Drug development and industrial pharmacy, 2011 37(10):1244-1252

31. Kamba, M.; Seta, Y.; Kusai, A.; Ikeda, M.; Nishimura, K. A unique dosage form to evaluate the mechanical destructive forces in the gastrointestinal tract. Int. J. Pharm., 2000, 208: 61-70.

32. Kamba M, Seta Y,Kusai A, Nishimura K, Evaluation of the mechanical destructive force in the stomach of dog. Int. J. Pharm., 2001, 228:209217.

\section{Citation:}

Patel G M and Patel J D: Single Core Osmotic Pump (SCOP): Development of Single Layer Osmotic controlled release tablet for poorly soluble drug. journal of Pharmaceutical Technology and Drug Research 2012, 1:1. http://dx.doi.org/10.7243/2050-120X-1-1 